Title: Protective efficacy of calcium phosphate nanoparticle adsorbed bivalent subunit vaccine of Pasteurella multocida against homologous challenge in mice

5 Agricultural University, Khanapara, Guwahati. 781022 (INDIA).

b Department of Veterinary Biochemistry, College of Veterinary Science, Assam

7 Agricultural University, Khanapara, Guwahati. 781022 (INDIA).

${ }^{c}$ Department of Veterinary Microbiology, College of Veterinary Science, Assam

9 Agricultural University, Khanapara, Guwahati. 781022 (INDIA).

10 Email Ids:

11 Dr. Songyukta Shyam: songyukta999@gmail.com

12 Dr. Shantanu Tamuly: drsan100@gmail.com

13 Dr. Probodh Borah: borahp@ vetbifg.ac.in

14 Dr. Rajeev Kumar Sharma: dr.sharmark@rediffmail.com

16 *corresponding author: Shantanu Tamuly,

17 Email: drsan100@gmail.com 


\section{IMPORTANCE OF THE WORK}

24 The swine pasteurellosis is an important economic disease affecting the pig

25 population in the North-eastern part of India that contributes the major pig population. The

26 disease is caused by Serotype A and D of Pasteurella multocida. At present the inactivated

27 vaccine is used that is actually developed against $\mathrm{P}_{52}$ strain of serotype $\mathrm{B}: 2$ of Pasteurella

28 multocida, which is mainly involved in haemorrhagic septicaemia (or bovine pasteurellosis)

29 that affects the cattle, buffaloe, sheep and goat. As a result, the present vaccine does not give

30 sufficient protection in pigs but gives significant protection in cattle, buffaloe, sheep and

31 goat. Hence, there is a need of development of vaccine that can address specifically swine

32 pasteurellosis by targeting serotype A and D of Pasteurella multocida. 


\section{ABSTRACT}

Swine pasteurellosis, caused by Pasteurella multocida capsular types A and D, causes

36 heavy economic loss to the pig farmers. The vaccine presently used is abacterin of Pasteurella

37 multocida capsular type B that is proven to be effective against bovine pasteurellosis.

38 However, its efficacy against swine pasteurellosis is questionable. The present study was

39 carried out to evaluate the efficacy of calcium phosphate nanoparticle adjuvanted bivalent

40 subunit vaccine prepared from Pasteurella multocida capsular types A and D along with a

41 monovalent subunit vaccine prepared from Pasteurella multocida capsular type B in mice.

42 The Alum precipitated bacterin vaccine was used as the control. The bivalent subunit vaccine

43 comprising the immune components of both the capsular types showed significantly higher

44 IgG response than either of the other two vaccines. Both the calcium phosphate nanoparticle

45 adjuvanted vaccines could elicit $100 \%$ protection in mice against homologous challenges but

46 the aluminum hydroxide adjuvanted bacterin vaccine could not elicit significant protection.

47 Based on this preliminary work, it was concluded that the bivalent subunit vaccine would be

48 a better option for immunization of swine against swine pasteurellosis. 


\section{INTRODUCTION}

52 Swine pasteurellosis is caused by Pasteurella multocida capsular types A and D, while

53 the capsular type B:2 of $P$. multocida is the causative agent of haemorrhagic septicaemia

54 (HS) that affects mainly cattle, buffalo, sheep and goat. Swine pasteurellosis is responsible

55 for significant economic loss to the pig industry in the north-eastern region of India. The

56 disease occurs in acute septicaemic as well as subacute pneumonic forms. Pneumonic forms

57 are caused by P. multocida of capsular types A and $\mathrm{D}^{1 \text { cited in } 2}$. There are also reports of acute

58 septicaemia caused by capsular type B organism ${ }^{3 c i t e d ~ i n 2}$. Swine pasteurellosis often occurs as

59 complications with swine fever, swine influenza and may also be associated with parasitic,

60 viral and other bacterial diseases or environmental factors that impair pulmonary function.

61 Presently in India, an alum- or oil-adjuvanted killed vaccine prepared from $P$.

62 multocida serotype B: $2\left(\mathrm{P}_{52}\right.$ strain) is used for control of swine pasteurellosis in endemic

63 areas. This vaccine is unable to elicit sufficient protective immune response against swine

64 Pasteurellosis as it is prepared from $\mathrm{P}_{52}$ strain of serotype $\mathrm{B}: 2$ of $P$. multocida that is efficient

65 in controlling bovine pasteurellosis. These vaccines have certain limitations, viz. alum

66 precipitated vaccine induces local reactions, elicits IgE antibody responses and generally fail

67 to induce cell mediated immunity. Therefore, the duration of immunity induced is only for 4

68 to 6 months. Alum type adjuvants are not effective for all antigens. Whereas, oil adjuvanted

69 vaccines being too viscous are difficult to inject in animals particularly during herd

70 vaccination and it has site-specific and pyrogenic responses. Outbreaks are still occurring in

71 endemic areas even after vaccination. The commercial vaccines prepared from $P$. multocida

72 serotype $\mathrm{B}: 2\left(\mathrm{P}_{52}\right.$ strain) has been successful in controlling HS but this serotype is generally

73 not involved in swine pasteurellosis. This necessitates the exploration of other vaccine

74 candidates that may ensure adequate protection against $P$. multocida capsular types A and D. 
Live vaccines have also been used in some areas but outbreaks attributed to

76 vaccine strains and sometime reversal to the virulent form limit the use of these vaccines.

77 Live vaccines using capsular type B: 3, 4 strains have been reported to be unsafe for primary

78 vaccination in young calves. The inactivated form of vaccine is widely used throughout the

79 world. Generally, they are poor immunogens thus require efficient adjuvant system.

80 Therefore, the development of more efficient and safe adjuvants, and vaccine delivery

81 systems to obtain high and long-lasting immune response is of utmost importance.

82 Various workers aimed at developing more effective vaccines by identifying

83 potential protective antigen(s) and formulating new vaccine adjuvants. The capsular

84 polysaccharide has shown induction of higher level of protection in rabbits when conjugated

85 with bovine serum albumin. Lipopolysaccharide of $P$. multocida has been found to be

86 partially immunogenic in mammals. Cattle and rabbits have not been readily protected

87 against $P$. multocida infection following immunization with LPS. Protein is an integral part

88 of the outer membrane of gram-negative bacteria and is found to be associated with

89 immunity ${ }^{4,5,6}$.Many different studies on outer membrane proteins (Omp) have shown that

90 they are major immunogens against homologous challenges in mammal ${ }^{7}$. The omps being

91 non-living vaccine candidates require an efficient adjuvant system for eliciting efficient

92 immune response ${ }^{8}$.

93 An ample amount of work has been carried out on oil and alum adjuvants, which

94 have respective drawbacks of poor syringability and site-specific reactions ${ }^{8}$.Some works were

95 carried out on exploration of calcium phosphate nanoparticles as an adjuvant. Nanoparticles

96 have recently been shown to possess significant potential as a drug delivery system. Studies

97 have showed significant adjuvanticity of calcium phosphate nanoparticles when complexed

98 with whole capsid proteins of virus and recombinant protein of bacteria ${ }^{9,}{ }^{10,}{ }^{11}$.Calcium

99 phosphate is a natural component the body and known to act by depot effect, anddue to its 
100 smaller size, facilitates efficient uptake by macrophages. The potential advantages of calcium

101 phosphate nanoparticles as an adjuvant are- 1. Reduce systemic side effect, 2. Efficiently

102 deliver antigens to antigen presenting cells (APCs), especially dendritic cells 3. Provide

103 sustained release of the encapsulated antigens (depot effect) ${ }^{12}$.

104 In the present study, the whole outer membrane proteins obtained from capsular types

$105 \mathrm{~A}$ and $\mathrm{D}$ (isolated from upper respiratory tract of pig)as well as the bacterin prepared from $\mathrm{P}_{52}$

106 vaccine strain of $P$. multocida were conjugated with calcium phosphate nanoparticles and

107 their protective efficacy was evaluated in mice.

108 MATERIALS AND METHOD

109 Bioethics permission:

110 The study was approved by the Institutional Animal Ethics Committee of Assam

111 Agricultural University, Khanapara, Guwahati-781022 (India) vide approval No.

112 770/ac/CPCSEA/FVSc/AAU/IAEC/13-14/191 dated 10-2-2014.

\section{Bacterial strains and media:}

114 The bacterial strains used in the present study were $\mathrm{P}_{52}$ strain (capsular type B:2) of $P$.

115 multocida, swine isolates of capsular types A and D of P. multocida obtained from the 116 repository of Department of Veterinary Microbiology, College of Veterinary Science, Assam

117 Agricultural University, Guwahati. The bacterial isolates were grown in brain heart infusion 118 broth (Hi-Media) at $37^{\circ} \mathrm{C}$ in shaking condition to mid-logarithmic phase.

\section{Isolation of whole outer membrane protein}

120 The whole outer membrane proteins were purified from revived isolates of capsular

121 types A, B, and D of P. multocida. Briefly, the glycerol stock of the isolates were streaked

122 onto a blood agar plate and incubated overnight at $37^{\circ} \mathrm{C}$. The single colonies were inoculated

123 into brain heart infusion broth (Hi-Media) and incubated at $37^{\circ} \mathrm{C}$ in shaking condition till the

124 mid-log phase. Then $0.1 \mathrm{ml}$ of culture was inoculated into Swiss Albino mice (Lacca strain) 
125 intraperitoneally. The organism was re-isolated from the heart blood, and its species and 126 capsular type was confirmed by $\mathrm{PM}$ specific $\mathrm{PCR}^{13}$ and capsular type specific $\mathrm{PCR},{ }^{29}$

127 respectively. The whole outer membrane proteins were extracted from all the three strains as

128 per the method described by Choi-Kim et al. ${ }^{15}$. The protein was quantified by the method

129 described by Lowry ${ }^{16}$. The presence of proteins were documented by one dimensional SDS-

130 PAGE, using 5\% stacking gel and $12 \%$ separating gel ${ }^{17}$.

131 Preparation of Calcium Phosphate Nanoparticle-adsorbed Outer Membrane Protein

\section{Conjugate (CAP-Omp)}

133 One $\mathrm{mg}$ of outer membrane protein $(0.5 \mathrm{mg}$ of OMP each from P. multocida of

134 capsular types A and D) was lyophilized in sterile conical flasks. This was followed by 135 addition of $7.5 \mathrm{ml}$ of $12.5 \mathrm{mM}$ calcium chloride, $7.5 \mathrm{ml}$ of $12.5 \mathrm{mM}$ dibasic sodium 136 phosphate solution and $1.5 \mathrm{ml}$ of $15.6 \mathrm{mM}$ sodium citrate. Flask containing the suspension 137 was stirred till the average particle size was less than $100 \mathrm{~nm}$. The suspension was 138 centrifuged at $800 \times \mathrm{g}$ for 20 minutes at $4^{\circ} \mathrm{C}$. The supernatant was discarded and the pellet was 139 washed with 0.1M PBS (pH 7.2). One ml cellubiose (129 mM) was added to the pellet and 140 kept for overnight at $4^{\circ} \mathrm{C}$. Four mg of OMP was added to the pellet with cellubiose and was 141 incubated at $4^{\circ} \mathrm{C}$ for 1 hour. The suspension was centrifuged at $800 \times \mathrm{g}$ for 20 minutes and the 142 pellet was lyophilized and kept in $-20^{\circ} \mathrm{C}$ till further use. The calcium phosphate nanoparticle-

143 OMP conjugate containing the OMP of $\mathrm{P}_{52}$ strain was made in a similar manner.

\section{Characterization of Nanoparticles}

145 The characterization of nanoparticles was done by transmission electron microscopy 146 in Indian Institute Technology, Guwahati. For transmission electron microscopy (TEM147 2100F), one drop of calcium phosphate nanoparticle suspension was put on parafilm. The 200 148 mesh copper carbon grid was soaked into the drop. The grid was placed on the filter paper 149 and the grid was allowed to dry for one hour. The dried grid was then placed inside the 
150 electron microscope chamber after creation of vacuum. The particles were viewed at 150,000

151 Xmagnification.

152 Estimation of Protein Load in the Complex (CAP-Protein):

153 The amount of protein load of calcium phosphate nanoparticle-OMP complex was

154 measured by using protocol of Joyappa et al. ${ }^{18}$. The known amount of calcium phosphate 155 nanoparticle-OMP complex pellet was taken in a microcentrifuge tube. The pellet was 156 suspended in 100mM EDTA solution and incubated at room temperature for 30 minutes. The 157 suspension was centrifuged at $800 \times \mathrm{g}$ for 20 minutes. The supernatant was taken in a fresh 158 tube and protein was estimated at $280 \mathrm{~nm}$ by spectrophotometry.

Immunization Protocol in mice

Twenty four Swiss Albino mice were divided randomly into four groups containing six mice in each group as depicted in Table 1.

Table1. Groups of mice injected with different vaccine formulations and their route of inoculation

\begin{tabular}{|l|l|c|}
\hline Groups & \multicolumn{1}{|c|}{ Material injected } & Route \\
\hline Group A & Calcium phosphate nanoparticle-outer membrane protein (capsular \\
& type A and D) complex $($ CAP-OMP(A+D)) & $\mathrm{s} / \mathrm{c}$ \\
\hline Group B & $\begin{array}{l}\text { Calcium phosphate nanoparticle-outer membrane protein complex } \\
\text { of } \mathrm{P}_{52} \text { strain }\left(\mathrm{CAP}-\mathrm{OMP}\left(\mathrm{P}_{52}\right)\right)\end{array}$ & $\mathrm{s} / \mathrm{c}$ \\
\hline Group C & $\begin{array}{l}\text { Calcium phosphate nanoparticle ( without incorporation of protein) } \\
\text { (CAP-Void) }\end{array}$ & $\mathrm{s} / \mathrm{c}$ \\
\hline Group D & Alum precipitated bacterin vaccine. & $\mathrm{i} / \mathrm{m}$ \\
\hline
\end{tabular}



groups A and B were injected with $100 \mu \mathrm{l}$ of vaccine preparation containing $100 \mu \mathrm{g}$ of OMP of P. multocida of capsular types A and D, and $100 \mu \mathrm{g}$ of OMP of serotype B: $2\left(\mathrm{P}_{52}\right.$ strain),

169 respectively. The mice in group $\mathrm{C}$ were injected with calcium phosphate nanoparticles

170 (without incorporation of protein) dissolved in 0.1M PBS (pH7.2). The mice of group D were

171 injected subcutaneously with $0.2 \mathrm{ml}$ of commercial alum adjuvanted bacterin vaccine

172 (obtained from Department of Veterinary Microbiology, College of Veterinary Science, 173 Assam Agricultural University).

174 The booster dose was administered on $14^{\text {th }}$ day after primary vaccination. Blood 175 samples were collected from the tail vein of mice on the day of primary vaccination and on 7 , 17614,21 and 28 days post primary vaccination. The serum was separated and stored at $-20^{\circ} \mathrm{C}$ 177 till further use.

$178 \quad$ Enzyme-Linked Immuno-Sorbant Assay

179 The serum IgG titre was tested indirect ELISA. Briefly, the ELISA 96 wells polysorb 180 microtiter plate was coated with either $200 \mathrm{ng}$ of OMP of Pasteurella multocida capsular type $181 \mathrm{~A}$ or $\mathrm{D}$ or $\mathrm{B}\left(\mathrm{P}_{52}\right)$ or $32 \mu \mathrm{g}$ of whole cell sonicated lysate of $\mathrm{P}_{52}$ strain of Pasteurella 182 multocida. The coated plates were stored at $4^{\circ} \mathrm{C}$ for overnight.

183 The plate was washed thrice with washing solution (PBS containing $0.05 \%$ Tween-20

$184 \mathrm{pH}$ 7.4). Hundred $\mu \mathrm{l}$ of blocking solution (2\% BSA in PBS) was added to each well and the 185 plate was kept at $37^{\circ} \mathrm{C}$ for one hour. The plates were washed thrice with washing solution.

186 Then $100 \mu \mathrm{l}$ of serially diluted serum was added to each well and the plates were incubated 187 for 2 hours at $37^{\circ} \mathrm{C}$. The plates were washed thrice with washing solution. Hundred $\mu 1$ of 188 anti-mouse HRP conjugated IgG antibody (1:2000) was added to each well and the plates 189 were kept for incubation for one hour at $37^{\circ} \mathrm{C}$. The OPD substrate solution $(24.3 \mathrm{mM}$ citric 190 acid, $51.4 \mathrm{mM}$ dibasic sodium phosphate, $0.4 \mathrm{mg}$ per $\mathrm{ml}$ orthophenyl diamine, $0.4 \mu \mathrm{l}$ per $\mathrm{ml}$ 
$191 \mathrm{H}_{2} \mathrm{O}_{2}$ ) was prepared during the time of incubation. The plates were washed thrice with

192 washing solution. Then $100 \mu \mathrm{l}$ of OPD substrate was added and the plates were incubated at 193 room temperature in dark for 30 minutes. Then $100 \mu \mathrm{l}$ of $1.5 \mathrm{~N} \mathrm{NaOH}$ was added to each well.

194 The OD was read in $492 \mathrm{~nm}$. The cut-off value was determined by mean OD of negative 195 control plus $2 \times$ Standard deviation. The titre was determined using regression analysis taking 196 OD value as predictor variable (x-variable) and reciprocal of $\log _{10}$ of serum dilution as 197 response variable (y-variable).

All groups were inoculated intra-peritoneally with virulent $P$. multocida capsular

200 types $\mathrm{A}$ or $\mathrm{D}$ at the dose rate of $100 \times \mathrm{LD}_{50}$ on $28^{\text {th }}$ day post primary vaccination. The animals 201 were observed for mortality or any kind of clinical symptoms for 72 hours. The re-isolation 202 of organism was attempted from the heart blood of dead mice using the method as mentioned 203 above under the section "Isolation of whole outer membrane protein".

$204 \quad$ Statistical Analysis:

The difference in humoral immunity between the groups were analyzed by one way

206 ANOVA and among the different days within the same group by one way repeated measures 207 ANOVA. The analysis of results of the animal challenge study was performed by Chi-square 208 test of independence using Yates's correction. The p-value of less than 0.05 was considered 209 significant and less than 0.01 was considered highly significant. The analysis was performed 210 with the statistical software R (R Core Team, 2019).

\section{RESULTS}

Protein profile of outer membrane protein of Pasteurella multocida capsular

\section{3 types A, D and B}

214 Protein profiles of OMPs were studied by employing 12.5\% SDS-PAGE. Coomassie

215 brilliant blue stained gel revealed six prominent OMP bands of capsular type A having the 
216 relative molecular weights $(\mathrm{Mr})$ ranging from 28.88 to $63.7 \mathrm{kDa}$; seven prominent $\mathrm{OMP}$

217 bands of capsular type D having Mr ranging from23.88 to $94.76 \mathrm{kDa}$ and three prominent

218 OMP bands of serotype type B: 2 ( $\mathrm{P}_{52}$ strain) having Mr ranging from20.38 to $47.95 \mathrm{kDa}$.

219 One OMP of Mr $47.95 \mathrm{kDa}$ was found to be commonly expressed in all the three capsular

220 types. On the other hand, the OMP of molecular weight $28.88 \mathrm{kDa}$ was found to be 221 commonly expressed in capsular type A and $\mathrm{P}_{52}$ strain of P. multocida.

\begin{tabular}{|l|l|l|}
\hline \multicolumn{2}{|l|}{ Relative molecular weights of OMPs in Kilo-Daltons } \\
(kDa) on the basis of electrophoretic migration in \\
SDS-PAGE & & strain \\
\hline Capsular type A & Capsular type D & P $_{52}$ vaccine \\
& 94.76 & 47.95 \\
\hline 63.7 & 75.91 & 33.83 \\
\hline 55.29 & 54.42 & 20.38 \\
\hline 47.95 & 47.95 & \\
\hline 41.57 & 42.24 & \\
\hline 33.83 & 28.88 & \\
\hline 28.88 & 23.88 & \\
\hline & & \\
\hline
\end{tabular}




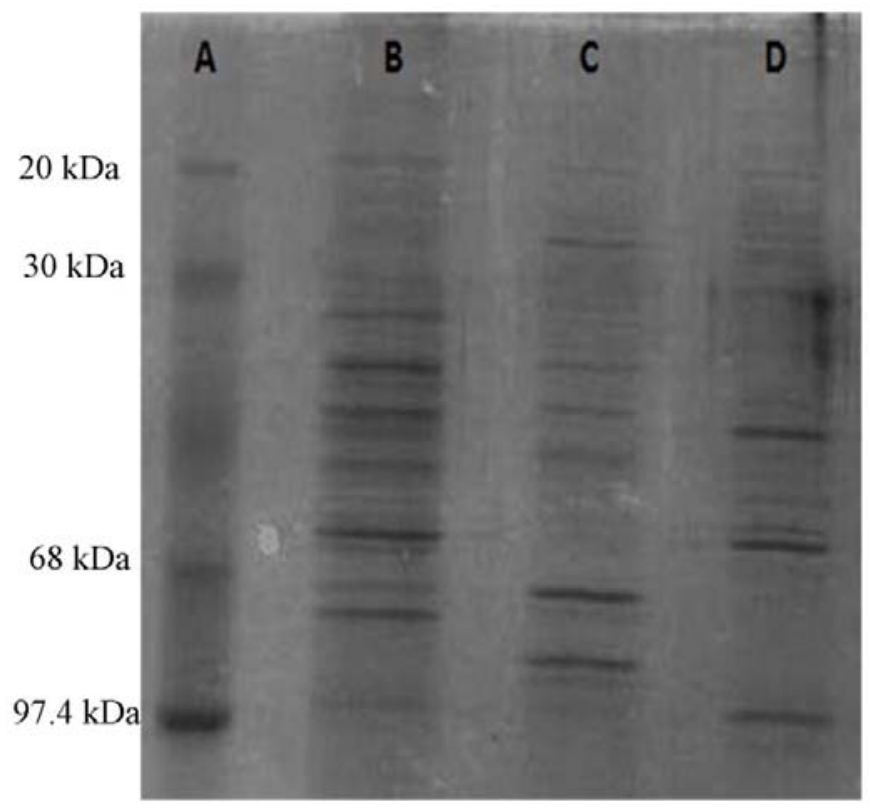

Fig. 1. Coomassie Brilliant Blue stained SDS-PAGE (12.5\%) profile of outer membrane proteins of $P$. multocida of different capsular types along with standard MW 230 markers

231 (Lane $\mathrm{A}=$ molecular marker; Lane $\mathrm{B}=P$. multocida capsular type $\mathrm{A}$; Lane $\mathrm{C}=P$. 232 multocida capsular type $\mathrm{D}$; Lane $\mathrm{D}=$ P. multocida capsular type $\mathrm{B}: 2$ ) 


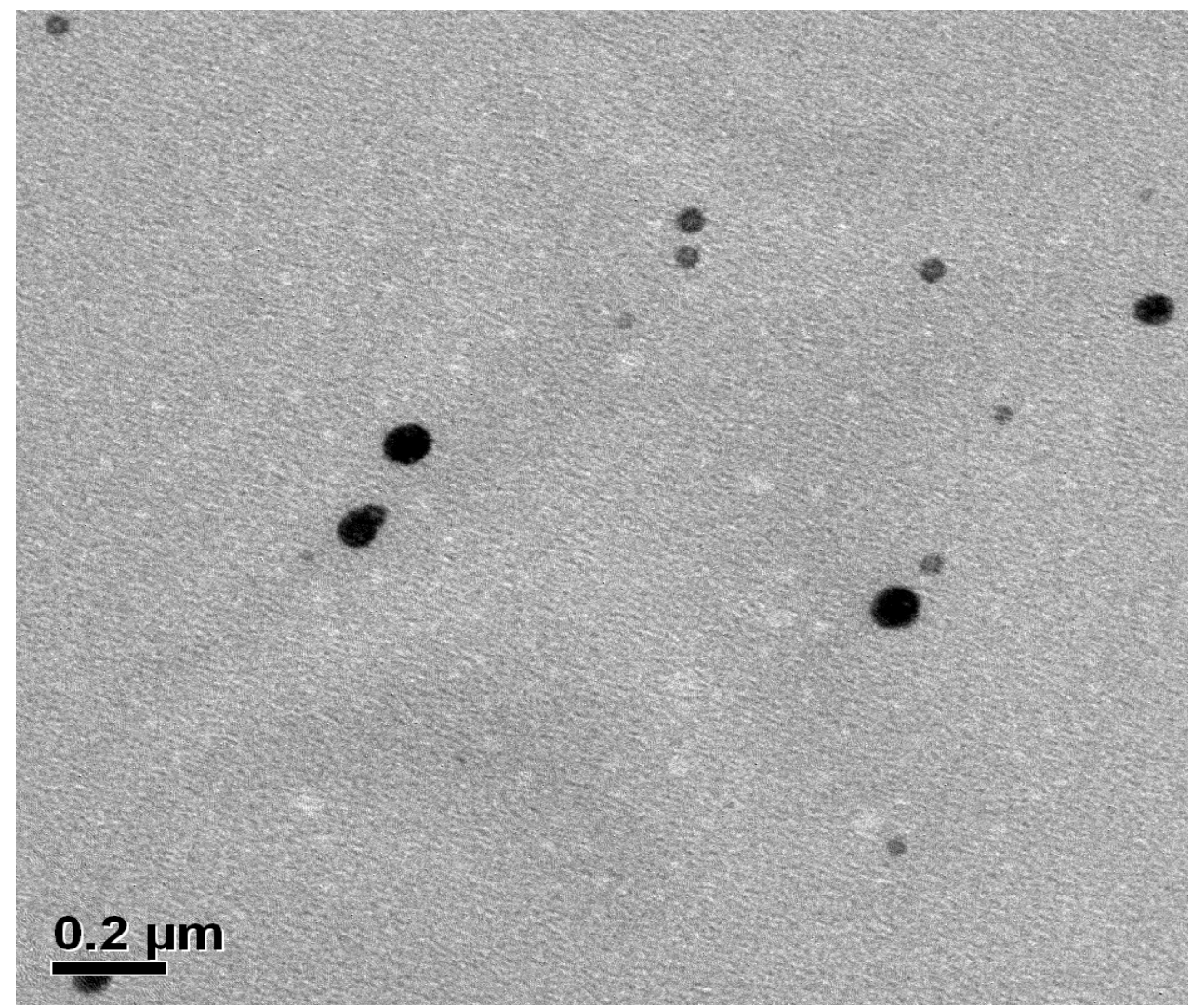

237 size was about $39.9 \mathrm{~nm}$ to $80 \mathrm{~nm}(150,000 \times$ magnification $)$.

Production of $\boldsymbol{P}$. multocida outer membrane protein loaded calcium phosphate

nanoparticle:

The conjugate of protein and calcium phosphate nanoparticle was characterized by

242 transmission electron microscopy. Majority of nanoparticles were of spherical morphology

243 with a diameter of $39.9 \mathrm{~nm}$ to $80 \mathrm{~nm}$. The distribution of size of the nanoparticlesis depicted

244 in Fig. 2. A total of $10 \mu \mathrm{g}$ protein could be loaded in $1 \mathrm{mg}$ of calcium phosphate

245 nanoparticles.

\section{Induction of anti-IgG response in mice}

The mean IgG titre against OMP of capsular type A in the group of mice vaccinated

248 with CAP-OMP-(A+D) increased up to 14 days after the primary vaccination. Following 
249 booster vaccination on the $14^{\text {th }}$ day, it increased slightly up to the $21^{\text {st }}$ day which started

250 declining on 28th day post primary vaccination; but there was no significant difference

251 between the $\mathrm{IgG}$ titres on 21 st day and 28 th day $(\mathrm{P}>0.05)$. The mean IgG titre against OMP

252 of capsular type D in the same group increased up to 14 days and was maintained till 28 days

253 as there were no significant difference between the titres recorded on $14^{\text {th }}$ day and $21^{\text {st }}$ dayas

254 well as between $21^{\text {st }}$ day and $28^{\text {th }}$ day $(\mathrm{P}>0.05)$.

255 The group of mice injected with CAP-OMP- $\left(\mathrm{P}_{52}\right)$ showed similar pattern of IgG

256 response as shown by CAP-OMP-(A+D) having the correlation of $97.94 \%$ and $98.62 \%$ for

257 IgG response against OMP of CapA and against CapD, respectively. The mean IgG titre

258 against OMP of capsular type A was found to be significantly higher in the group injected

259 with CAP-OMP- $(\mathrm{A}+\mathrm{D})$ than that of the group injected with CAP-OMP- $\left(\mathrm{P}_{52}\right)(\mathrm{P}<0.01)$. The

260 mean IgG titre of the group of mice injected with bacterin vaccine was found to be

261 significantly lessercompared to that of the other two vaccinated groups.

262 The mean IgG response in all the groups against OMP of capsular type D increased

263 up to 7 days post-primary vaccination and then it was maintained up to the $28^{\text {th }}$ day. The mean

$264 \operatorname{IgG}$ titre of the alum-adjuvanted bacterin vaccinated group rose up to 14 days but it started

265 declining from 21 days even after booster vaccination on the $14^{\text {th }}$ day post-primary

266 vaccination. 


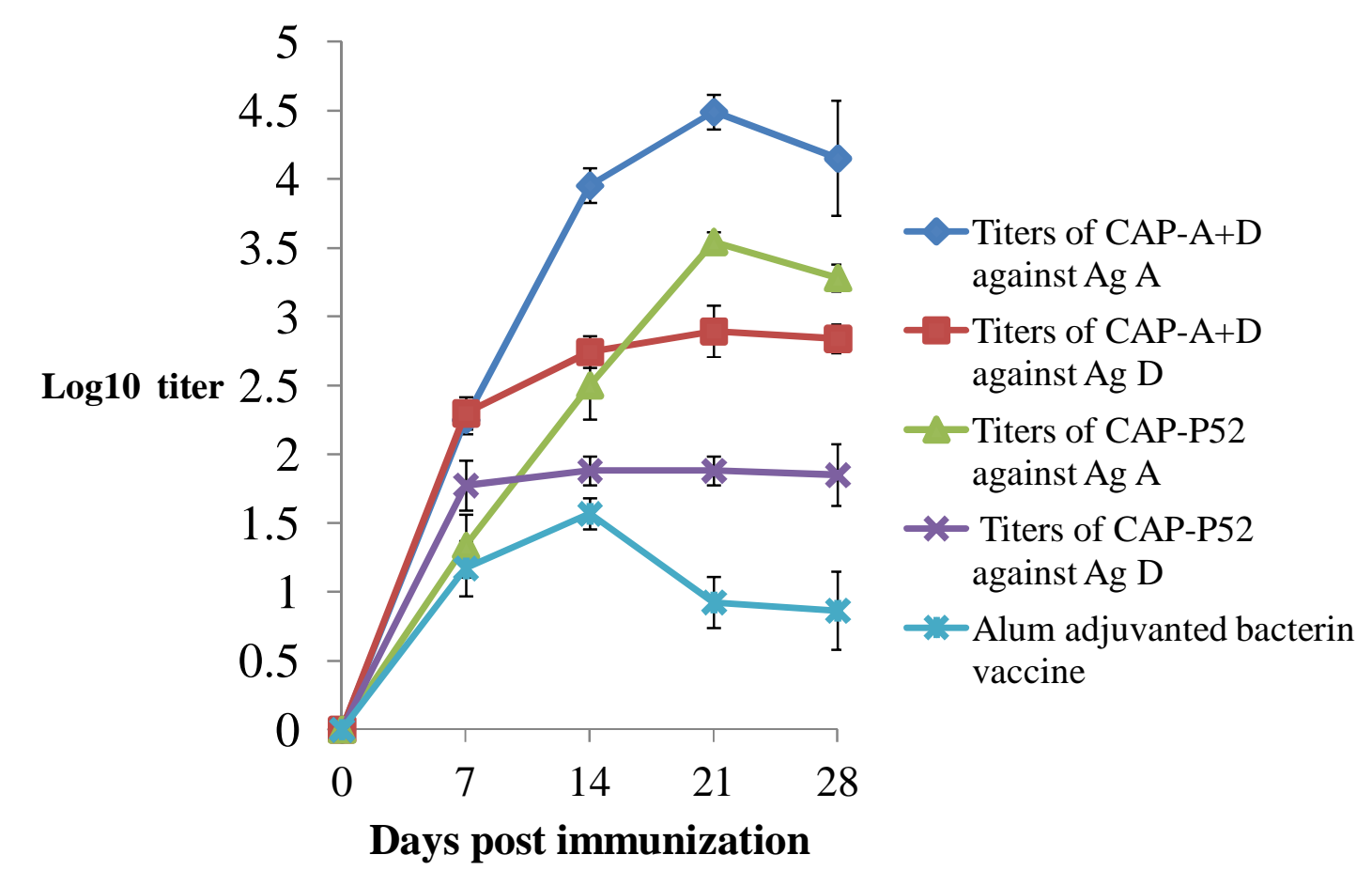

Fig. 3. The graphical representation of mean $\log _{10} \operatorname{IgG}$ titre of different groups of mice

271 against outer membrane protein of Pasteurella multocida capsular type A or D. against outer membrane protein of Pasteurella multocida capsular type A (The different alphabets between column and different roman numbers between different rows indicate statistically significant difference $(\mathrm{P}<0.05))$.

$\log _{10} \operatorname{IgG}$ titre against OMP of Pasteurella multocida capsular type A

\begin{tabular}{|l|l|l|l|l|}
\hline Groups & 7 & 14 & 21 & 28 \\
\hline A & $2.25 \pm 0.1^{1, \mathrm{~A}}$ & $3.95 \pm 0.13^{\mathrm{I}, \mathrm{B}}$ & $4.49 \pm 0.15^{\mathrm{I,B}}$ & $4.15 \pm 0.42^{\mathrm{I}, \mathrm{B}}$ \\
\hline $\mathrm{B}$ & $1.33 \pm 0.23^{\mathrm{III}, \mathrm{A}}$ & $2.5 \pm 0.25^{\mathrm{II}, \mathrm{A}}$ & $3.54 \pm 0.07^{1, \mathrm{~A}}$ & $3.28 \pm 0.1^{1, \mathrm{~A}}$ \\
\hline C & $1.17 \pm 0.2^{\mathrm{II}, \mathrm{A}}$ & $1.56 \pm 0.11^{\mathrm{II}, \mathrm{B}}$ & $0.86 \pm 0.18^{\mathrm{II}, \mathrm{C}}$ & $0.92 \pm 0.28^{\mathrm{II}, \mathrm{C}}$ \\
\hline
\end{tabular}



against outer membrane protein of Pasteurella multocida capsular type D (The different

IgG titre Against OMP of Pasteurella multocida capsular type D

\begin{tabular}{|l|l|l|l|l|}
\hline Groups & 7 & 14 & 21 & 28 \\
\hline A & $2.3 \pm 0.12^{\mathrm{I}, \mathrm{A}}$ & $2.74 \pm 0.12^{\mathrm{I}, \mathrm{A}}$ & $2.89 \pm 0.19^{\mathrm{I}, \mathrm{A}}$ & $2.84 \pm 0.1^{\mathrm{I}, \mathrm{A}}$ \\
\hline B & $1.77 \pm 0.18^{\mathrm{III}, \mathrm{A}}$ & $1.88 \pm 0.1^{\mathrm{III}, \mathrm{A}}$ & $1.88 \pm 0.1^{\mathrm{III}, \mathrm{A}}$ & $1.85 \pm 0.23^{\mathrm{II}, \mathrm{A}}$ \\
\hline C & $1.17 \pm 0.2^{\mathrm{IIIIII}, \mathrm{A}}$ & $1.56 \pm 0.11^{\mathrm{II}, \mathrm{III}, \mathrm{A}}$ & $0.86 \pm 0.18^{\mathrm{II}, \mathrm{A}}$ & $0.92 \pm 0.28^{\mathrm{III}, \mathrm{A}}$ \\
\hline
\end{tabular}

The challenge study indicated that both the vaccine formulations containing calcium phosphate nanoparticles as adjuvant elicited $100 \%$ protection against challenge with either $P$. multocida capsular type A or D. On the other hand, the mice belonging to the group injected with alum adjuvanted bacterin showed the survivability of 50\% and $33.33 \%$ when challenged with P. multocidaof capsular types A and D, respectively.

294 Table 5. Protection of mice immunized with calcium phosphate nanoparticles -OMP of 295 capsular types A and D and calcium phosphate nanoparticles - OMP of P52 and alum 296 adjuvanted bacterin vaccine

\begin{tabular}{|c|c|c|c|c|}
\hline GROUP & Dose and & & Post challenged \\
& Immunizations schedule & Challenging & Post & death \\
\hline
\end{tabular}




\begin{tabular}{|c|c|c|c|c|c|c|c|}
\hline & Primary & Secondary & $\begin{array}{c}\text { capsular } \\
\text { type }\end{array}$ & $\begin{array}{c}\text { challenged } \\
\text { survival }\end{array}$ & 24 hours & $\begin{array}{c}48 \\
\text { hours }\end{array}$ & $\begin{array}{c}72 \\
\text { hours }\end{array}$ \\
\hline \multirow[t]{2}{*}{ CAP-OMP } & \multirow[t]{2}{*}{$100 \mu \mathrm{g}$} & \multirow[t]{2}{*}{$50 \mu \mathrm{g}$} & A & $100 \%(6 / 6) *$ & nil & nil & nil \\
\hline & & & $\mathrm{D}$ & $100 \%(6 / 6)^{*}$ & nil & nil & nil \\
\hline \multirow{2}{*}{$\begin{array}{c}\text { CAP- } \\
\text { OMP(p52) }\end{array}$} & \multirow[t]{2}{*}{$100 \mu \mathrm{g}$} & \multirow[t]{2}{*}{$50 \mu \mathrm{g}$} & A & $100 \%(6 / 6) *$ & nil & nil & nil \\
\hline & & & $\mathrm{D}$ & $100 \%(6 / 6)^{*}$ & nil & nil & nil \\
\hline $\begin{array}{c}\text { alum } \\
\text { adjuvanted }\end{array}$ & \multirow{2}{*}{$\begin{array}{c}4 \times 10^{8} \\
\text { cfu/mice }\end{array}$} & \multirow{2}{*}{$\begin{array}{c}4 \times 10^{8} \\
\text { cfu/mice }\end{array}$} & A & $50 \%(3 / 6)^{* *}$ & nil & 1 & 2 \\
\hline $\begin{array}{c}\text { adjuvanted } \\
\text { bacterin }\end{array}$ & & & $\mathrm{D}$ & $\begin{array}{l}33.33 \% \\
(2 / 6) * *\end{array}$ & nil & 1 & 1 \\
\hline CAP-PBS & ---------- & -------- & -do- & $0 \%(0 / 6)$ & nil & 4 & 2 \\
\hline PBS & ---------- & -------- & -do- & $0 \%(0 / 6)$ & nil & 3 & 3 \\
\hline \multicolumn{8}{|c|}{ *Indicates significant association between vaccination and survivability. } \\
\hline
\end{tabular}

\section{DISCUSSION}

Pasteurella multocida of serotype $\mathrm{B}: 2$ ( $\mathrm{P}_{52}$ strains) is widely recognized as a

301 causative agent of haemorrhagic septicemia of cattle and buffaloes ${ }^{9}$. Capsular types A and D

302 cause economic losses in swine because of their association with progressive atrophic rhinitis

303 and enzootic pneumonia ${ }^{1}$.Their association with acute septicaemia in pigs has been 
304 recognized $^{3}$.Pasteurella multocida is a part of the commensal microflora in the upper

305 respiratory tract of pigs. The organism was shown to appear intermittently in the naso-

306 pharynx and subsequently shed in nasal secretions ${ }^{20}$.During such period, the carrier animal

307 becomes a source of infection for in-contact susceptible animals. Pasteurella multocida has

308 been classified into five serogroups on the basis of capsular antigens- A, B, D, E and

$309 \mathrm{~F}^{21}$.Besides their variable geographical distribution, these serogroups are more or less specific

310 with regard to their host. ${ }^{4}$ Capsular types A \& D cause economic losses in the swine industry

311 because of their association with progressive enzootic pneumonia, also known as pneumonic

312 pasteurellosis while atrophic rhinitis is associated with the capsular type $\mathrm{D}^{23}$.

313 Although several vaccines are used to control bovine pasteurellosis

314 (Haemorrhagic septicemia), no vaccine is currently available for controlling swine

315 pasteurellosis in India. Therefore occurrence of the disease in many regions of the country

316 has been reported ${ }^{18,24,25}$. The SDS-PAGE banding patterns of OMP of Pasteurella multocida

317 of capsular types A, D and B in the present study revealed significant differences which could

318 be the possible reason behind the less efficiency of conventional vaccine prepared from

319 capsular type $\mathrm{B}\left(\mathrm{P}_{52}\right.$ strain) in protecting pigs against swine pasteurellosis. As both the

320 capsular types of A and D are involved in swine pasteurellosis, it would be prudent to use a

321 bivalent vaccine containing the immune components of both the capsular types. The present

322 study was carried out to assess the comparative efficacy of three vaccine formulations, viz. the

323 calcium phosphate nanoparticle adjuvanted OMP based vaccines, either bivalent (containing

324 OMP of capsular types A and D) or monovalent (containing OMP of $\mathrm{P}_{52}$ strain of $P$.

325 multocida). The conventional alum adjuvanted bacterin vaccine prepared from $\mathrm{P}_{52}$ strain of $P$.

326 multocida was used as the control vaccine. The outer membrane proteins of $P$. multocida

327 have been studied by various workers for their importance in development of subunit vaccine

328 as the outer membrane proteins are known to play important role in interaction of bacteria 
329 with the host's epithelial cells and in virulence ${ }^{4}$.Though the outer membrane proteins are

330 good immunogens, they require the help of an efficient adjuvant or delivery system that can

331 aid in antigen uptake by antigen presenting cells. The alum based adjuvants have been used

332 for many years but they face the drawback of causing site specific inflammatory

333 reactions ${ }^{24}$.Nanoparticles based adjuvants are reported to efficiently stimulate the antigen

334 uptake by antigen presenting cells ${ }^{10,26}$.

335 The calcium phosphate nanoparticles were prepared using co-precipitation method.

336 The maximum protein that could be loaded inside the calcium phosphate nanoparticle was 10

$337 \mu \mathrm{g}$ per mg of calcium phosphate nanoparticle-OMP conjugate. The nanoparticles were easy to

338 disperse in aqueous medium.Joyappa et al. ${ }^{18}$ reported loading of $50 \mu \mathrm{g}$ plasmid DNA per mg

339 of calcium phosphate nanoparticle-DNA conjugate. The variation of loading of DNA and

340 protein (as in present study) could be due to the difference in biophysical properties of DNA

341 and protein. The method of preparation of calcium phosphate nanoparticles is easier and can

342 be efficiently used for production of vaccine in industrial scale. It takes nearly 18 hours to

343 prepare the calcium phosphate nanoparticle-outer membrane protein conjugate. On the other

344 hand, the double micro-emulsion method described by Bisht et al. ${ }^{27}$ for conjugation of

345 calcium phosphate nanoparticle with DNA appears to be more difficult to perform and 346 expensive.

347 The immunological studies indicated that the vaccine containing bivalent outer 348 membrane proteins of capsular types A and D of $P$. multocida elicited better anti-capsular 349 type A or D IgG response compared to that of the vaccine formulation containing outer 350 membrane proteins of $\mathrm{P}_{52}$ strain. This could be due to significant antigenic variations 351 observed in the outer membrane proteins of capsular types A, D or B of $P$. 352 multocida.However, both the vaccine formulations were able to elicit $100 \%$ protection against 353 both homologous or heterologous challenges. This could probably be due to the presence of 
354 common OMP band of relative molecular weight 47.95 kilodaltons in all the three capsular

355 types. This protein might have some relationship with $47 \mathrm{kDa}$ hypothetical protein reported

356 by Wheeler (2009), which is known to be expressed by P. multocida in wide range of

357 hosts $^{28}$.It was reported to be one of the immunogenic porin proteins that is involved in long

358 chain fatty acid transport across the cell membrane ${ }^{25}$. On the other hand, the bacterin vaccine

359 containing alum adjuvant could not elicit significant level of protection against the challenges

360 either with capsular types A or D of $P$. multocida. This could be due to masking of the

361 immunogenic outer membrane proteins by the lipopolysaccharide of the outer membrane of

362 the intact inactivated bacteria.

363 Although both the vaccine formulations containing either the OMP of $\mathrm{P}_{52}$ strain or

364 bivalent OMP of capsular types A and D of P. multocida showed $100 \%$ protection, the later

365 vaccine formulation showed significantly higher IgG response against capsular type A in

366 mice.

367 As the first report of use of bivalent OMP based vaccine using calcium phosphate 368 nanoparticles, the present study has showed that the vaccine formulation could elicit better

369 immune response compared to that of alum adjuvanted bacterin in mice. Further study is

370 required to assess its protective efficacy in pigs against swine pasteurellosis.

\section{ACKNOWLEDGEMENT}

The authors are grateful to the Centre Director, DBT-AAU Centre, Assam

373 Agricultural University, Jorhat, Assam, India for providing financial support to carry out the 374 work. The authors are also grateful to the Advanced State Biotech Hub, College of Veterinary

375 Science, AAU, Guwahati for providing the laboratory facilities.

\section{REFERENCES}



47(8), 679-688. Assam. Indian J. Anim Res., 2010, 44(4), 265-269. outer membrane protein of Pasteurella multocida in buffalo calves. Vet. Microbio., 1996, 52(3-4), 301-311. experimental challenge exposure. Am. J. Vet. Res., 1995, 56(7), 875-879. iron-restricted medium. J. Appl. Anim. Res., 1998, 13(1-2), 137-144. 
8. Cox, J.C. and Coulter, A.R., Adjuvants-a classification and review of their modes of action. Vaccine. 1997, 15(3), 248-56. Immunol, 2000,7(6), 899-903. nanoparticles induce mucosal immunity and protection against herpes simplex virus type 2. Clin. Diagn. Lab. Immunol. 2002, 9(5), 1021-1024. Outermembrane Protein 87 (Omp87) of Pasteurella multocida (Serotype B:2) in Mice. Journal of nanopharmaceutics and drug delivery. 2014, 2(1), 80-86. vaccine adjuvants and delivery systems: regulation of immune responses by nanoparticle-based vaccine. In Polymers in nanomedicine. 2011;31-64. identification of Pasteurella multocidaisolates. J. Clin.Microbiol., 1998, 36(4),1096-1100. Genetic organization of Pasteurella multocida cap loci and development of a multiplex capsular PCR typing system. J.Clin.Microbiol., 2001, 39(3), 924-929. 

28(1),75-92. measurement with the Folin phenol reagent. J. Biol.Chem.. 1951;193(1):265-75. $2001 ; 3^{\text {rd }}$ eds. Vet. J., 1992, 148(2), 99-112.

20. Confer, A.W., Update on bacterial pathogenesis in BRD. Anim. Health Res. Rev.,2009, 10, 145-148. hemolytica. Adv. Vet. Sci., 1967, 11, 321-379. composition, function and genetics. J. Biotechnol., 2000, 83(1-2),153-60. 361. 
calcium phosphate and aluminium hydroxide with different physical properties.

Vaccine. 1997, 15(12-13),1364-1371.

25. Prasannavadhana, A., Kumar, S., Thomas, P., Sarangi, L.N., Gupta, proteome analysis of Indian strain of Pasteurella multocida serotype B: 2 by MALDI-TOF/MS analysis.Sci. World. J., 2014 vaccine delivery systems. Pharm.Res., 2014, 31(10), 2563-2582. phosphate nanoparticles: highly efficient non-viral vector for gene delivery. Int. J. Pharm., 2005, 288(1), 157-168. 